\title{
CRISE DO CAPITAL E ATUAIS TENDÊNCIAS DA (DES)PROTEÇÃO SOCIAL: TRAÇOS ILUSTRATIVOS DA SEGURIDADE SOCIAL BRASILEIRA
}

CAPITAL CRISIS AND CURRENT TRENDS OF SOCIAL (UN)PROTECTION:

ILUSTRATIVE FEATURES OF THE BRAZILIAN SOCIAL SECURITY.

\author{
Diego da Conceição Piedade ${ }^{1}$ \\ Potyara Amazoneida P. Pereira ${ }^{2}$
}

\section{RESUMO}

Este artigo trata da crise do capital na atualidade e de seus efeitos sociais deletérios. Discute a particularidade sistêmica e estrutural da referida crise, diferenciando-a de outras modalidades, mais frequentes, de caráter setorial, cíclico e conjuntural, observáveis inclusive nas formações sociais pré-capitalistas. Faz distinção entre capitalismo e capital para realçar o fato de o capitalismo ser o primeiro modo de produção no qual o capital não é um simples intermediário, mas o eixo. Não obstante situar a crise no contexto mundial e problematizá-la em sua totalidade realça suas implicações no subfinanciamento do Sistema de Seguridade Social brasileiro.

PALAVRAS-CHAVE: Crise do Capital. Proteção Social. Seguridade Social.

\section{ABSTRACT}

This article deals with the capital crisis at the present time and its deleterious social effects. It discusses the systemic and structural features of that crisis, differentiating it from other sectorial, cyclical and circumstantial more frequent modes, observable even in the precapitalist social formations. It makes a distinction between capitalism and capital to highlight the fact that capitalism is the first mode of production in which capital is not a simple intermediary, but the axis. Regardless situate the crisis in the global context and problematizing it in its entirety, it highlights their implications for the underfunding of the Brazilian Social Security System.

KEYWORDS: Capital Crisis. Social Protection. Social Security

\footnotetext{
${ }^{1}$ Bacharel em Serviço Social pela Universidade Federal do Recôncavo da Bahia - UFRB e Mestrando do Programa de Pós-Graduação em Política Social, do Departamento de Serviço Social, da Universidade de Brasília - UnB. Telefone: (61) 31077487. E-mail: diegotrumpet16@hotmail.com. 2 Professora do Programa de Pós-Graduação em Política Social (PPGPS) do Departamento de Serviço Social da Universidade de Brasília - UnB, líder do Grupo de Estudos Político-Sociais (POLITIZA), do PPGPS, inscrito no diretório de Grupos de Pesquisa do CNPq e Vice-Coordenadora do Núcleo de Estudos e Pesquisa em Política Social (NEPPOS), do Centro de Estudos Avançados Multidisciplinares (CEAM), da UnB. Telefone: (61) 31077487. E-mail: potyamaz@gmail.com.
} 


\section{INTRODUÇÃO}

Ao empreendermos esta análise - que tem como eixo a crise do capital e sua repercussão no sistema de proteção social ${ }^{3}$ no Brasil - elegemos a perspectiva históricodialética, por partirmos do princípio de que o conhecimento da realidade social é um movimento de apreensão de dinâmicas produzidas pela atividade humana e inerentemente contraditórias.

Ao fazer esse esclarecimento queremos, de início, informar que o referencial teórico no qual nos apoiamos rejeita ideias preconcebidas e interpretações ecléticas, visto que ambas distorcem os fatos pesquisados. As primeiras porque somente a realidade pode indicar o caminho a ser trilhado pelo pesquisador para desvendá-la; e, as segundas, porque a mistura de teorias inscritas em matrizes dissonantes de pensamento deturpa o conhecimento alcançado. É como diz Carcanholo (2012), ao se referir à teoria marxiana do valor que, no Brasil, tem sido filtrada (leia-se violada), por uma leitura ricardiana (tributária do economista político liberal clássico David Ricardo):

[...] no Brasil, na última década, a teoria do valor de Marx efetivamente se incorporou ao debate acadêmico e às salas de aula das universidades. Marx passou a se fazer presente nas discussões sobre a teoria econômica, mas - em nossa opinião - distorcido em seu verdadeiro conteúdo, modificado pela postura e ótica ricardianas. O que alguns no Brasil e também em outras partes, chamam de neomarxismo (ou até, muitas vezes de marxismo propriamente dito) no campo da teoria econômica, não é mais do que um ricardianismo de esquerda [...] profundamente influenciado pelas perspectivas teóricas delimitadas por uma postura reformista (p. 17).

Da mesma forma, o afastamento de esquemas metodológicos contidos em manuais será por nos privilegiado. Em vista disso, efetuaremos uma reflexão crítica na qual também a política social é encarada como processo internamente contraditório que resulta de correlações de forças gestadas no confronto de interesses de classes mediado pelo Estado.

\footnotetext{
${ }^{3}$ Segundo Boschetti (2012) “a constituição das políticas sociais em sistemas de proteção social públicos é recente e só será assim concebida a partir da crise de 1929. Isso porque um sistema de proteção social não é somente a justaposição de programas e políticas sociais, nem tampouco se restringe a uma política social, o que significa dizer que as políticas sociais não constituem em si mesmas um sistema de proteção social. O que o configura é o conjunto organizado, coerente, sistemático e planejado de políticas sociais que garantem a proteção social por meio de amplos direitos, bens e serviços sociais, nas áreas de emprego, saúde, previdência, habitação, assistência, educação” (p. 756).
}

Serv. Soc. \& Saúde, Campinas, SP v. 15, n. 1 (21), p. 51-70, jan./jun. 2016 ISSN 1676-6806 
Este texto tematiza elementos fundamentais da crise do capital neste tempo histórico, refletindo acerca dos processos de formação, reprodução e acumulação do modo de produção capitalista. Crise esta que deixou de ser apenas “cíclica”, segundo Mandel (1975; 1990), para assumir proporções estruturais, conforme Mészáros (2009), pelo fato de ela ser cumulativa, crônica e permanente e, portanto, avessa a correções de rumos reformistas. Assim, tanto nos países do capitalismo central quanto do periférico, há manifestações de sua presença caracterizadas pelo desemprego aberto, degradação ambiental, desmonte dos direitos sociais e um extraordinário aumento das desigualdades sociais.

Essa estrutura econômico-social perversa, que “mundializa” a barbárie, soma-se, no Brasil, à formação e desenvolvimento de uma frágil proteção social, que tem como prioridade a “inclusão, em canto nenhum dos excluídos”, contribuindo, contraditoriamente, para o fortalecimento não só da agenda capitalista, mas também das seculares e retrógadas relações entre trabalho e capital.

O alto grau de informalização do trabalho no Brasil, associado às políticas de “ativação” para um mercado laboral precário e flexível, que não garante a autossustentação do trabalhador, como prevê o receituário neoliberal, submete a classe que vive do seu próprio trabalho a condições aviltantes de assalariamento e de cidadania.

\section{A mundialização da crise e seus efeitos deletérios}

A tematização dos elementos fundamentais da crise do capital exige que façamos, com base em Mészáros (2009) e Mandel (1975; 1982), respaldados em Marx,

a distinção entre capital e capitalismo. Mészáros afirma “que 'capital' é uma categoria histórica dinâmica e a força social a ela correspondente aparece na forma de capital 'monetário’, 'mercantil' etc. vários séculos antes da formação social do capitalismo” (p. 121). Trata-se, na consideração de Mandel (1982), de um valor que se incrementa com mais valor, seja por meio da usura (capital usurário), da circulação de mercadorias (capital mercantil ou comercial) - como acontecia nas sociedades feudais, semifeudais e no modo de produção asiático - seja por meio da produção capitalista. Em todos esses casos, a produção de bens já não se destina, exclusivamente, ao consumo direto dos 
produtores. Todavia, no capitalismo - o primeiro modo de produção nascido da penetração do capital no processo produtivo (MANDEL, 1982), o capital não mais desempenha papel de intermediário, mas se apropria dos meios de produção, penetrando inteiramente na produção propriamente dita.

Eis porque a crise capitalista é sempre de superprodução movida pelo metabolismo irrefreável do capital em busca de lucro incessante (MÉSZÁROS, 2009). Conforme Mandel (1975), tal crise não decorre exatamente da fome, da escassez de riqueza e de alimentos, da falta de trabalhadores e da diminuição do rendimento do trabalho, como acontecia nas formações sociais pré-capitalistas; mas resulta da abundância de mercadorias, cujo encalhe diminui a taxa de lucro de seus proprietários levando vários à ruína e à recorrência à ajuda do Estado. Além disso, a crise do capital, no capitalismo, é algo que não mais se restringe ao âmbito local, pois este modo mais avançado de produção tem como pressuposto a universalização das mercadorias produzidas, abarcando, por isso, a maioria dos países que se conectam em um sistema onde o capital transcende fronteiras. Daí a sua generalidade e tendência à mundialização ${ }^{4}$. E daí também a nossa preocupação em analisar este tipo particular de crise do capital só verificável no modo capitalista de produção.

Sabe-se que no ciclo de formação do capital o trabalho desempenha papel fundamental. Este é o denominador comum inconteste. Porém, no capitalismo, o trabalho não é apenas um produtor coletivo de valor, mas é apropriado privadamente, diminuído no seu tempo de produção de valor de uso e estendido na sua capacidade de gerar mais valor em prol da reprodução cada vez mais ampliada do capital. Marx diferencia esse processo de produção de valor e de mais valor nos seguintes termos:

[...] comparando o processo de produzir valor com o de produzir mais valia, veremos que o segundo só difere do primeiro por se prolongar além de certo ponto. O processo de produzir valor simplesmente dura até o ponto em que o valor da força de trabalho pago pelo capital é substituído por um equivalente. Ultrapassando esse ponto, o processo de produzir valor torna-se processo de produzir mais valia (valor excedente) (MARX, 1980, p. 220).

\footnotetext{
${ }^{4}$ Tal como Chesnais, preferimos usar a expressão 'mundialização do capital' e não 'globalização da economia' porque, em inglês, a palavra global refere-se tanto a fenômenos ligados à (ou às) sociedades humanas no sentido do globo como tal (é o caso da expressão "global warming" que significa "efeito estufa”), quanto a processos cuja característica é ser 'global' unicamente na perspectiva estratégica de um ‘agente econômico’ ou de um ‘ator social’ específico (CF. CHESNAIS, 2001, p. 12).

Serv. Soc. \& Saúde, Campinas, SP v. 15, n. 1 (21), p. 51-70, jan./jun. 2016 ISSN 1676-6806
} 
Portanto, o trabalho que assume conotações diferentes daquele que apenas produz valor de uso e que subsidia a acumulação do capital, torna-se, no modo de produção capitalista, trabalho assalariado: um trabalho cuja remuneração é sempre menor que o tempo por ele utilizado e cujo excedente é arbitrariamente apropriado pelo empregador. Nesse processo de exploração do trabalho pelo capital, as contradições que lhe são inerentes produzem e reforçam os períodos de crise, revelando que o desenvolvimento global do modo de produção capitalista não pode se subordinar à noção de “equilíbrio” (MANDEL, 1982). Esse desenvolvimento corresponde, mais precisamente, a uma unidade dialeticamente contraditória de períodos de equilíbrio e desequilíbrio, a saber:

[...] cada período de equilíbrio conduz inevitavelmente a um desequilíbrio, que, por sua vez, após certo tempo, torna possível um novo e provisório equilíbrio. Mais ainda, uma das características da economia capitalista é que não apenas as crises, mas também o crescimento acelerado da produção - não apenas a reprodução interrompida, mas também a reprodução ampliada - são governadas pelas rupturas de equilíbrio (ibid., p.17).

Vê-se, assim, que o processo de crise e equilíbrio do capital é inerente a sua própria forma de reprodução e retroalimentação. Para tanto, há necessidade constante de reformulação de seu processo de acumulação, por meio da diminuição dos dispêndios na produção e da busca excessiva de mais-valia (MANDEL, 1982).

Atualmente essa busca tem se valido dos mecanismos de crédito como uma das “mediações decisivas” (BEHRING, 2012, p. 156). A propriedade privada dos meios de produção ganha rentabilidade por meio de operações monetárias solventes, nas quais prevalece o domínio do capital financeiro de forma mundializada. De acordo com Chesnais,

[...] as formas mais concentradas do capital - capital financeiro predominantemente industrial ou capital de investimento financeiro "puro" - beneficiam-se, então, de um campo de operações e de um espaço de dominação que se estende sobre grande parte do planeta, ou mesmo a totalidade se estimarmos que a integração da China ao capitalismo mundial está perto de acontecer (p. 8).

Foi, portanto, a partir da conglomeração de instituições financeiras, como bancos, corporações de seguro, capital agroexportador - na sua relação com o Estado, tanto em momentos de concessão ideológica, tendo em vista a manutenção de poder, 
quanto nos desvios do "fundo público" em tempos de crise - que o processo de acumulação rentista se legitimou.

Chesnais (2001) observa que só se consegue esse desenvolvimento e aprofundamento a partir da inter-relação do campo econômico com o político, ressaltando que “é apenas na vulgata neoliberal que o Estado é 'exterior' ao 'mercado' (p.10). Essa inter-relação pode ser observada nos nexos de poder que os Estados Unidos estabelecem com os demais países. A produção militarista tem desempenhado papel “maquiador" e de fortalecimento da hegemonia ${ }^{5}$ imperialista $^{6}$ dos Estados Unidos, somada às operações de empréstimos a países com endividamento potencial. Segundo Mészáros (2009), esse domínio norte-americano conserva elementos que servem de reafirmação de sua longa hegemonia no mundo ocidental, tais como: extraterritorialidade; vantagem industrial do sigilo militar; pressões comerciais diretas exercidas pelo legislativo e executivo; problema real da dívida e antagonismo político resultante da penetração econômica.

Essa condição privilegiada dos Estados Unidos também contribuiu para a legitimação do "mercado”, como pressuposto a seguir, desde a adoção da ideologia neoliberal pelos governos Ronald Reagan, dos Estados Unidos (1981-1989), e Margareth Thatcher, da Grã Bretanha (1979-1990). Consequentemente, o discurso sobre a "superioridade do mercado" e a "retração necessária do Estado" explorou ao máximo, segundo Chesnais (2001), a imensa desordem política nascida do balanço radicalmente negativo do "socialismo real” (p. 11). Isso sem falar da transformação dos Estados Unidos em única potência mundial em decorrência da autodissolução da União Soviética em 1991.

Problematizando o imperialismo norte-americano, Harvey (2008) faz menção à construção de um importante aparato ideológico que conseguiu criar, em torno se si,

\footnotetext{
${ }^{5}$ Em conformidade com Acanda (2002) que, baseado em Gramsci, define hegemonia como "la capacidad de la classe dominante de obtener y mantener su poder sobre la sociedad, no sólo por su control de los médios de producción económicos y de los instrumentos repressivos, sino sobre todo porque es capaz de producir y organizar el consenso y la dirección política, intelectual y moral de la misma" (251).

${ }^{6}$ Para Harvey (2004), o imperialismo capitalista resulta da “fusão contraditória entre a política do Estado e do império (o imperialismo como projeto distintivamente político da parte dos atores cujo poder se baseia no domínio de um território e numa capacidade de mobilizar os recursos naturais e humanos desse território para fins políticos, econômicos e militares) e "os processos moleculares de acumulação do capital no espaço e no tempo (o imperialismo como um processo político-econômico difuso no espaço e no tempo no qual o domínio e o uso do capital assumem primazia)" (p. 31).
}

Serv. Soc. \& Saúde, Campinas, SP v. 15, n. 1 (21), p. 51-70, jan.jjun. 2016 ISSN 1676-6806 
consenso e legitimidade internacionais; e com ele os neoliberais moldaram o que viria a ser um pressuposto bem-sucedido de domínio sem rival dos Estados Unidos.

A concepção de "liberdade e dignidade humana”, veiculada por essa ideologia, age como um mantra que consegue reunir solidariedades em relação à “nacionalidade”, aos valores e aspirações estadunidenses. Foi assim que os governantes norte-americanos elaboraram uma concepção de "ataque a sua liberdade” para legitimar a invasão e a consequente guerra no Iraque (HARVEY, 2008).

Apesar de haver maior debate em torno da configuração financeira da crise do capital atualmente em curso, concordamos com Mészáros (2009) quanto ao fato de não haver dúvidas de que esta crise é sistêmica, além de estrutural. As turbulências financeiras não são as únicas verificadas. Desde a segunda metade do século XIX há uma regularidade temporal de momentos rápidos de equilíbrio e de "crises cíclicas” no capitalismo; e, de forma objetiva, nota-se a superação dessas crises com mais acumulação (NETTO, 2012, p. 415).

Para Netto (2012), portanto, estamos vivendo uma crise que possui traços particulares em relação à maioria das que lhe antecederam: seu conteúdo não é apenas financeiro, embora este seja o aspecto mais evidenciado. Trata-se de um tipo de crise que

[...] o capitalismo experimentou integralmente, até hoje, por apenas duas vezes: a chamada crise sistêmica, que não é uma mera crise que se manifesta quando a acumulação capitalista se vê obstaculizada ou impedida. A crise sistêmica se manifesta envolvendo toda a estrutura da ordem do capital (p. 415).

Tal processo de crise adquire propriedades que invadem a vida social na sua imediaticidade, seja por meio da precarização e desarticulação do “mundo do trabalho”, seja pelo processo cultural do consumo induzido.

Como não poderia deixar de ser, a nação brasileira sofreu e sofre os efeitos deletérios desta crise, embora tenha se apresentado, no discurso oficial, como relativamente imune a ela. Behring (2009), apoiada em Mandel, afirma que, em 1974, o Brasil já aparecia como o "primeiro lugar na tabela dos déficits do balanço de pagamentos” (p. 148). E informa que, naquela ocasião,

[...] os efeitos da recessão foram catastróficos: a alta dos preços do petróleo bem como dos preços dos víveres e fertilizantes químicos levaram a um agravamento do déficit do balanço de pagamentos; a queda dos preços das matérias-primas e a redução do volume das 
exportações levaram a uma diminuição dos recursos em divisas, dificultando o enfrentamento das despesas (BEHRING, 2009, p. 148).

Recentemente, assinala a autora, a forte onda de estagnação verificada no país foi também impulsionada por esses processos, responsáveis pelo decréscimo de setores econômicos importantes, assim como pelo aumento da dívida pública. Esses acontecimentos têm forte ligação com a entronização do ideário neoliberal no Brasil, nos anos 1990, e com a reconfiguração do Estado brasileiro no bojo de uma sociedade de classes em que a burguesia ainda preserva valores escravocratas ao tempo em que se mantém dependente dos países capitalistas centrais.

Não à toa o desvio do fundo público nacional para amortizar a dívida externa é um fator que nutre a supremacia da retroalimentação do capital sobre o compromisso público com o atendimento das demandas e necessidades da população. A esse respeito, serão apresentados, na próxima seção, e a guisa de ilustração, dados da "Auditoria Cidadã da Dívida”, uma vez que o orçamento público ${ }^{7}$, como uma dimensão do fundo público, tem direta influência nas políticas sociais. O subinvestimento das políticas de Seguridade Social, por exemplo, e sua direta implicação na qualidade de vida dos trabalhadores, justifica este destaque. Afinal, "os números da mais recente crise são contundentes, tanto quanto os indicadores do empobrecimento generalizado das maiorias, especialmente na periferia do mundo do capital, além do desemprego em expansão em todas as quadras do mundo” (BEHRING, 2010, p. 32).

\section{Proteção social no Brasil em contexto de crise: um hóspede necessário ou indesejado?}

A proteção social à brasileira se desenvolveu de forma fragmentada, tímida e limitada. Segundo Oliveira (2008), “as contradições da sociedade capitalista, explicitadas na produção coletiva de riquezas e na sua apropriação privada estão na base

\footnotetext{
${ }^{7}$ Segundo Salvador (2012) “o orçamento público é quem garante concretude à ação planejada do Estado e espelha as prioridades das políticas públicas. O fundo público deve assegurar recursos suficientes para o financiamento das políticas sociais. Contudo, não basta a análise de como os recursos são alocados; uma questão fundamental é como as políticas sociais são financiadas, ou seja: sobre quem recai o financiamento do Estado? ” (p. 124).

Serv. Soc. \& Saúde, Campinas, SP v. 15, n. 1 (21), p. 51-70, jan./jun. 2016 ISSN 1676-6806
} 
da questão social e do surgimento das políticas sociais ou dos sistemas de proteção social” (p. 109).

As políticas sociais, como componentes e mediações dessa proteção, inserem-se num processo de conflitos de interesses, típico das sociedades divididas em classes antagônicas: ao capital é lícito pugnar por mais e mais lucros e aos trabalhadores é admissível pleitear por melhores salários e condições laborais. Este pleito - vale lembrar - representou uma das primeiras conquistas trabalhistas no terreno dos direitos de cidadania, que imprimiram, no Estado burguês, postura contraditória: ao mesmo tempo em que atendia as pressões do capital, comprometia-se com as garantias sociais no mundo do trabalho. Ou como diz Pereira (2011),

[...] na prática, a ingerência do Estado na realidade social é tão antiga, que só quem não esteja disposto a reconhecê-la não a percebe. Mesmo nos regimes liberais mais ortodoxos, expressamente avessos à intervenção estatal, o Estado sempre interveio politicamente para atender demandas e necessidades, seja na esfera do trabalho, seja na esfera do capital (p. 99).

Percebe-se, assim, que o Estado $^{8}$ burguês, na sua relação com a sociedade, tem papel relevante na formação e desenvolvimento das políticas sociais e econômicas. Entre as reflexões sobre essa relação ressalta a pertinente qualificação de Jorge Acanda (2002) do termo "sociedade civil".

Segundo este autor, a denominação “sociedade civil” surgiu com o liberalismo clássico, nos séculos XVIII e XIX, com o objetivo de restringir os poderes do Estado e constituir um mecanismo privado independente. Por esse prisma, "a racionalidade da sociedade identifica-se com a racionalidade do mercado capitalista e é entendida como superior à atividade política do Estado que por isso não deve interferir” (ACANDA, 2002, p. 134. Tradução nossa).

Eis porque, o receituário neoliberal dos tempos correntes confere à sociedade civil papel “interventor” no campo que deveria ser ocupado pelo Estado, atribuindo àquela responsabilidade tanto pelo "sucesso" individual e coletivo, quanto pelas vicissitudes sociais. Contrapondo-se a essa visão, Acanda (2002) remete-se a Gramsci

\footnotetext{
${ }^{8}$ Segundo Pereira (2011), o pensamento marxiano em relação ao Estado é de desconfiança quanto a sua possibilidade de proporcionar verdadeiro bem-estar: o "Estado só seria necessário onde uma classe dominante, possuidora dos meios de produção (proprietários de escravos, senhores feudais e capitalistas) se apropriasse do produto do trabalho da classe explorada (escravos, servos da gleba e proletários)” (p. 104).

Serv. Soc. \& Saúde, Campinas, SP v.15, n. 1 (21), p. 51-70, jan./jun. 2016 ISSN 1676-6806
} 
para lembrar que a sociedade civil é “o espaço no qual se produzem e difundem as representações ideológicas” (p. 252, tradução nossa) ou, conforme Durighetto (2008), também referenciada em Gramsci: “é o espaço em que as classes organizam e defendem seus interesses” (p. 84). Por conseguinte, é na sociedade civil que a classe trabalhadora tem conseguido impor limites políticos e sociais ao despotismo do capital.

Nos países capitalistas centrais, onde a proteção social adquiriu forma mais abrangente, datando do período compreendido entre os anos “dourados”9 de 1945 a 1975, as políticas sociais potencializaram os efeitos dessa proteção. Suas “estratégias pleno emprego, direitos sociais amplos e universais, sustentação da demanda efetiva e do consumo - estiveram na base dos sistemas de proteção social na Europa ocidental” (BOSCHETTI, 2012, p. 758), constituindo mecanismos de contenção da crise de 1929.

Chesnais (2001), ao se reportar ao contexto recente da crise do capital e considerando a “sorte reservada aos países 'em desenvolvimento', tal qual o Brasil, alerta para a busca incessante do capitalismo por lucros ampliados, por meio das “instituições que vivem dos rendimentos”. E complementa:

[...] a avidez deste capitalismo e sua ferocidade na exploração são tanto mais altas quanto a taxa de acumulação do capital produzindo valor e mais-valia é baixa, enquanto as exigências daqueles que vivem de juros e de dividendos são mais elevadas (p. 22).

Não à toa o Brasil vem servindo, desde os anos 1990, de plataforma emergente de valorização financeira internacional, graças à adoção de políticas de "securitização da dívida externa, de internacionalização do mercado de títulos públicos e abertura dos fluxos internacionais de capital” (PAULANI, 2010, p. 133).

A historiografia do pensamento econômico brasileiro revela como as ideologias burguesas contribuíram para o estágio atual da vida nacional. O “desenvolvimentismo"10 como integrante de uma passagem histórica, segundo Castelo (2012), teve sua primeira experiência no governo Vargas, no estado do Rio Grande do

\footnotetext{
9 Termo equivalente aos “trinta anos gloriosos", cunhado pelos franceses, para indicar o período em que vigorou nos países capitalistas centrais, notadamente os do norte da Europa ou da Escandinávia, um padrão de política social cujo denominador comum era a existência de uma classe trabalhadora consciente de seus direitos e a prevalência de um regime socialdemocrata de bem-estar.

${ }^{10}$ De acordo com Mota (2012), o desenvolvimentismo seria “uma ideologia econômica que sustentava o projeto de industrialização integral, com participação do Estado como forma de superar o atraso da pobreza dos países subdesenvolvidos” (p. 156).
}

Serv. Soc. \& Saúde, Campinas, SP v. 15, n. 1 (21), p. 51-70, jan./jun. 2016 ISSN 1676-6806 
Sul, em 1928, sob o nome de nacional-desenvolvimentismo. A simbiose entre investimentos financeiros privados, por meio de incentivos estatais, colocou o projeto de desenvolvimento governamental em funcionamento, marcando um novo modo de relações entre Estado e burguesia. Ou, mais precisamente: “operou-se, a articulação de um novo bloco de poder, com uma aliança entre o Estado e uma burguesia nacional emergente, sem, contudo, romper totalmente com as antigas classes dominantes, notadamente os latifundiários” (ibid., p. 619).

Castelo apresenta elementos que caracterizam o empreendimento desenvolvimentista adotado pelos governos brasileiros antes do golpe civil-militar de 1964. Este processo se deu entre períodos de lutas anti-imperialistas, junção das burguesias internacional, nacional e o Estado e a tentativa de reformas de base, mas foi surpreendido pelo advento da ditadura ${ }^{11}$ e o aprofundamento do capital financeiro (ibid., p. 620). Sobre a condução do desenvolvimentismo no período de ditadura - pois esta também abraçou esse projeto - Castelo informa que:

[...] os grupos progressistas - dos trabalhistas aos comunistas, dos reformistas aos revolucionários - que apoiavam em maior ou menor grau o nacional-desenvolvimentismo foram derrotados e massacrados por uma ditadura civil-militar de vinte anos, e o desenvolvimentismo tomou novos rumos sob o tacão de ferro dos militares, da tecnocracia estatal e da burguesia, hegemonizada pelos monopólios internacionais (p. 620).

Nesse contexto, o “milagre econômico", caracterizado por um significativo aumento do Produto Interno Bruto (PIB), entre 1968 e 1973, verificou-se, mas sem que o almejado desenvolvimento tenha ocorrido, devido à manutenção da dependência do país ao capitalismo internacional e ao aumento da inflação e da concentração de renda (ibid., p. 621). Na década de 1990, sob a égide do neoliberalismo, propagou-se o falso

\footnotetext{
${ }^{11}$ Segundo Sampaio Jr. (2012), “iniciado no Brasil em 1964 e encerrado no Chile em 1973, o ciclo latinoamericano de golpes militares que instauram ditaduras do grande capital determina o desfecho do processo de revolução burguesa no continente como uma contrarrevolução permanente. O regime do capital consolida-se na América Latina como um capitalismo dependente. Apoiados pelo império norteamericano, os setores pragmáticos interromperam violentamente o processo de reformas estruturais cristalizando, definitivamente, a dupla articulação dependência externa e segregação social - como alicerce fundamental da acumulação de capital na região. A contrarrevolução jogou por terra os sonhos desenvolvimentistas. O regime burguês sedimentou-se como uma sociedade mercantil particularmente antissocial, antinacional e antidemocrática. A superexploração do trabalho tornou-se parâmetro estratégico do padrão de acumulação. A intolerância em relação à utilização do conflito como meio legítimo de conquistas coletivas converteu-se na quintessência do padrão de dominação. Pobreza e miséria se transformaram definitivamente na galinha de ovos de ouro da burguesia latino-americana. Acabava a ilusão de um capitalismo civilizado” (p. 676).
}

Serv. Soc. \& Saúde, Campinas, SP v.15, n. 1 (21), p. 51-70, jan./jun. 2016 ISSN 1676-6806 
discurso de um desenvolvimento social atrelado ao desenvolvimento econômico. Mas, foi a partir dos anos 2000 que, segundo Mota (2012),

[...] os governantes ou candidatos que pleiteavam a representação dos chamados setores progressistas da sociedade chegam ao poder com posicionamentos anti-imperialistas e a defesa do desenvolvimento nacional, compreendido como um meio de autonomia dos estados nacionais. Não se trata de uma repetição do desenvolvimentismo nacional dos anos 1960, mas da defesa de um desenvolvimento autossustentável desde o ponto de vista econômico e social (p. 155).

Surge assim o “neodesenvolvimentismo”, como uma aspiração intelectual e ideológica, do governo Lula ${ }^{12}$. Calçado na retomada do crescimento econômico, na valorização do poder de compra do salário, na crescente distribuição da renda pessoal, no endividamento das famílias e no “mito” da relativa imunidade do país à crise mundial, Lula colocou essa aspiração no centro de sua gestão. Mas ela não ultrapassou “as fronteiras da 'província' e, mesmo no seu interior, circunscreveu-se a pequenos círculos acadêmicos” (SAMPAIO JR., 2012, p. 678).

Corroborando a análise de Gonçalves (2011), Boschetti (2013), indica que a recente retomada do "nacional desenvolvimentismo” se opôs à experiência original, entre 1930 a 1980. Na verdade, segundo ela, o "novo desenvolvimento" da era Lula poderia ser sintetizado como um padrão de desindustrialização; reprimarização das importações; maior dependência tecnológica; desnacionalização; perda de competitividade internacional; crescente vulnerabilidade externa; maior concentração de capital; dominação financeira (p. 359).

Foi nessa conjuntura que o Sistema de Seguridade Social, previsto na Constituição da República do Brasil, de 1988, composto das políticas de Previdência Social, Saúde e Assistência Social, se processou a duras penas, haja vista os ataques que lhes foram desferidos pela ofensiva neoliberal então introduzida no país. Nessa Constituição estava previsto um Orçamento em separado - o da Seguridade Social gerido pelo Estado, o qual sofreu fortes injunções referentes às “disponibilidades de caixa” (BEHRING, 2013, p. 20). Consequentemente, em momentos de crise, os gastos sociais quedaram-se extremamente limitados e penalizados por mecanismos do “ajuste

\footnotetext{
${ }^{12}$ Castelo (2012) afirma que, na América Latina, os governos, apesar de defenderem o rompimento com o neoliberalismo, assumiram essa ideologia após sua posse, demonstrando com isso que "o governo Lula [constituiu] o caso mais emblemático dessa adesão ao projeto de supremacia burguesa” (p. 624).
} 
fiscal” (ibid.). Em 2008, Behring já alertava para a dívida do Estado, associada à política de superávit primário, imposta pelo Fundo Monetário Internacional (FMI), e para o comprometimento do fundo público com as táticas de “salva-vidas” do capital um mecanismo de nefasta incidência nos recursos da Seguridade Social. Segundo a autora,

[...] o superávit primário é alimentado por um mecanismo criado no âmbito do Plano Real e que hoje se chama Desvinculação de Receitas da União - DRU - que desvincula $20 \%$ das receitas de impostos e contribuições sociais. Este mecanismo de manipulação orçamentária foi prorrogado pela recente "reforma" tributaria até 2007, e em fins de 2007 (BEHRING, 2008, p. 51).

Com base em outros indicadores, Fattorelli e Ávila (2012; 2014) têm feito, a partir da “Auditoria Cidadã da Dívida”, a comparação entre a destinação orçamentária, referente à dívida pública, e a da Seguridade Social. Em 2012, dizem eles, a dívida assumiu a maior fatia dentro do Orçamento Geral da União, sob a forma de juros e amortizações da dívida (47,19\%), enquanto no Orçamento da Seguridade Social a Previdência aparecia com 18,22\%, a Saúde com 3,98\% e a Assistência Social com 2,55\%. Se juntarmos nesse cálculo o conjunto das políticas sociais que não fazem parte do Sistema de Seguridade Social, a Educação aparece com 3,18\%, o Transporte com 1,21\%, a Cultura com 0,09\% e a Habitação com 0,05\%. Isso desmonta o “mito”, apontado por Behring, da incolumidade brasileira aos efeitos da crise, sendo esta uma estratégia dos organismos financeiros para que os países adotem suas imposições e medidas.

Atualizando esses dados em 2014, a Auditoria Cidadã da Dívida mostra que, apesar da diminuição da destinação orçamentária para o pagamento da dívida externa esta, por ter sido acanhada, continua como protagonista no conjunto da destinação geral do Orçamento da União. Os juros e amortizações da dívida aparecem, em 2014, com 45,11\% enquanto a Previdência contempla 21,76\%, a Saúde 3,98\% e a Assistência Social 3,08\%. Se novamente juntarmos nesse cálculo o conjunto das políticas sociais que estão fora do Sistema de Seguridade Social, a Educação exibe parcos 3,73\%, o Transporte 0,56\%, a Cultura 0,04\% e a Habitação 0,00\%.

Esses dados revelam uma dinâmica “inversa” na pauta de prioridades dos investimentos no Brasil ou uma "perversa alquimia”, nos termos de Boscchetti e 
Salvador (2006), o que faz com que o fundo público converta-se em uma forma de incentivo ao capital.

Em relação à Previdência Social os trabalhadores vêm enfrentando momentos de retrocessos de direitos conquistados por meio de lutas históricas. Segundo Lopes (2015), decisões autoritárias têm sido adotadas pelo governo brasileiro, tais como as Medidas Provisórias nº 664 e 665, que impõem mudanças severas e conservadoras na “pensão por morte, auxílio-doença, aposentadoria por invalidez, auxílio-reclusão, abono salarial, seguro-desemprego e seguro defeso” (2015, p. 5).

Na Saúde o retrocesso consiste na privatização e concessão de seu comando à iniciativa privada. Tal é o caso da

Medida Provisória n. 520, de 31 de dezembro de 2010, que cria a Empresa Brasileira de Serviços Hospitalares (EBSERH), uma empresa pública com personalidade jurídica privada, sem qualquer espaço de controle social, conforme preconizado pela legislação do SUS. Esta empresa tem a possibilidade de administrar não só os hospitais universitários, mas qualquer unidade hospitalar no âmbito do SUS por meio de contrato de gestão. A EBSERH, como prevê a proposta de Fundações Estatais de Direito Privado, poderá contratar funcionários por CLT e por contrato temporário de até dois anos, acabando com a estabilidade e implementando a lógica da rotatividade, típica do setor privado, comprometendo a continuidade e a qualidade do atendimento (BRAVO, 2011, p. 187).

A Assistência Social, por fim, apesar do avanço de seu processo de institucionalização, a partir da Lei Orgânica da Assistência Social (LOAS), Política Nacional de Assistência Social (PNAS), Sistema Único de Assistência Social (SUAS) e demais marcos regulatórios, tem priorizado programas focalizados, com contrapartidas e corte de renda ínfimo para o acesso aos benefícios, a exemplo do Bolsa Família. Também vem sendo imposto a essa política uma incumbência autoritária de "ativação" de seus demandantes para o mercado de trabalho precário e desprotegido como forma de libertá-los da proteção pública. Dessa feita, realimenta-se a histórica tensão entre Assistência Social e Trabalho, mencionada por Boschetti (2003).

Outra questão ponderável diz respeito à moradia. Esta, que constitui nos dias de hoje uma pauta crucial, tendo em vista o processo “desordenado” de urbanização nacional, teve o seu percentual orçamentário rebaixado de 0,05\%, em 2012, para 0,00\%, em 2014. 
Face a essa realidade, e mesmo sabendo que o financiamento não é em si mesmo o fator determinante do bem-estar coletivo, cabe, diante da ausência de políticas de conteúdo substantivamente “social”, formular a seguinte questionamento: Como afirmar que o Brasil tenha vivido, a partir de 2003, um novo desenvolvimento? Tal indagação apoia-se na constatação evidenciada de que a proteção social colocada em prática fazendo jus ao seu movimento contraditório - melhorou as condições de vida da classe trabalhadora para mantê-los “de pé” e funcionais à dinâmica incontrolável de produção de mais capital.

Este é a promessa traiçoeira que o capital oferece aos trabalhadores: sobreviver sob seus desígnios para fortalecê-lo, por meio da venda mal remunerada de sua força trabalho; do consumo de bens e serviços (incluindo os sociais) como mercadorias; da absorção mecânica e mimética da cultura capitalista e da privatização de tudo o que público.

\section{PALAVRAS FINAIS}

Em suma, pensar o processo de formação e desenvolvimento das crises do capital tem constituído, simultaneamente, um esforço de compreensão da realidade e de prospecção de estratégias necessárias à subversão do secular domínio do capital sobre o trabalho. A “mundialização" desse domínio, no modo mais avançado do sistema do capital - o capitalista - tem tornado essa subversão muito mais difícil dado o limite imposto pelas “fronteiras” às possibilidades de uma revolução internacionalizada.

No quadro apresentado, a condição de extraterritorialidade é apenas desempenhada pelo movimento de financeirização e hegemonia capitalista capitaneada pelos Estados Unidos e legitimada pelos demais países. O domínio das instituições financeiras e o "pouso" dos órgãos de “integração entre os países” no solo norteamericano é o exemplo de que a formação e a relação entre o consenso e a produção militarista têm fornecido profícuos resultados para aquele país.

Como a economia tem se tornado cada vez mais importante em relação à política, a ausência de questionamento a respeito dos estragos causados pela supremacia antissocial daquela, bem como pelas práticas obscuras do setor financeiro, tem contribuído para o declínio e “quebra” das soberanias nacionais. 
No Brasil, o desvio do fundo público para satisfazer a gula insaciável do capital demonstra e confirma essa tendência. Com maior destinação para o pagamento da dívida, o país é afetado e obrigado a contar com uma baixa dotação orçamentária para colocar em prática suas políticas sociais.

Acreditamos, por conseguinte, que estamos passando de uma proteção social de baixa intensidade e abrangência para uma situação preocupante de crescente desproteção pública. Para confirmar esta tendência basta verificar mais a fundo o cenário e as condições em que se encontra proteção: alto grau de privatização; focalização extremada na pobreza; deslocamento da lógica do direito; escravização dos trabalhadores e império de uma ética na qual o mérito individual, baseado na competição desleal e na cobiça, penaliza todos os que não conseguem acessar o bemestar por meio do consumo autossustentado. Nesta forma de sociabilidade,

[...] a riqueza material se converte na medida de todas as coisas. Fomenta-se e expande-se uma autêntica idolatria do dinheiro e da riqueza. O espírito do lucro torna-se consubstancial à condição humana, da mesma forma que o egoísmo é enaltecido como o elemento dinamizador da necessária competência requerida para o progresso da sociedade. A ávida busca do lucro é considerada uma atitude elogiável nos indivíduos, ainda que esse lucro seja desmesurado, e o status que proporciona o poder econômico alcançado pela prática da cobiça é considerado o cume da respeitabilidade (BURGAYA, 2015, p. 255. Tradução nossa).

Por fim, cabe expressar que temos consciência de que este texto contém mais inquietações do que respostas; inquietações que - esperamos - conduzam a um repensar crítico da problemática aqui tratada e a novos e aprofundados estudos que apontem alternativas ou, pelo menos, um horizonte sem “neblinas”.

Recebido em 24.02.2016 - Aprovado em 12.04.2016

\section{REFERENCIAS}

ACANDA, J. L. A. Sociedad civil y hegemonia. Centro de Investigación y Desarrollo de la Cultura Cubana Juan Marinello, Habana: Cuba, 2002.

BEHRING, E. R. Acumulação capitalista, fundo público e política social. In: BOSCHETTI, I. et al. (Orgs.). Política social no capitalismo: tendências contemporâneas. São Paulo: Cortez, 2008. 
BEHRING, E. R. Política social no capitalismo tardio. São Paulo: Cortez, 2009.

BEHRING, E. R. Crise do capital, fundo público e valor. In: BOSCHETTI, I. et al. (Orgs.). Capitalismo em crise, política social e direitos. São Paulo: Cortez, 2010. BEHRING, E. R. Rotação do capital e crise: fundamentos para compreender o fundo público e a política social. In: SALVADOR, E. et al. (Orgs.). Financeirização, fundo público e política social. São Paulo: Cortez, 2012.

BEHRING, E. R. França e Brasil: realidades distintas da proteção social, entrelaçadas no fluxo da história. Serviço \& Sociedade, São Paulo, n. 113, p. 7-52, jan./mar. 2013. BOSCHETTI, I. Assistência Social no Brasil: um direito entre originalidade e conservadorismo. 2. ed. rev. ampl. Brasília: Gesst/SER/UnB, 2003. BOSCHETTI, I. A Insidiosa Corrosão dos Sistemas de Proteção Social Europeus. Serviço Social \& Sociedade, São Paulo, n. 112, p. 754-803, out./dez. 2012. BOSCHETTI, I. Políticas de desenvolvimento econômico e implicações para as políticas sociais. SER Social, Brasília, v.15, n. 33, p. 261-384, jul. / dez. 2013. BOSCHETTI, I.; SALVADOR, E. Orçamento da seguridade social e política econômica: perversa alquimia. Serviço Social \& Sociedade, São Paulo, v. 87, p. 25-57, 2006.

BRAVO, M. I. S. Frente Nacional contra a privatização e sua luta em defesa da saúde pública estatal. Serviço Social \& Sociedade, São Paulo, n. 105, p. 185-193, jan./ mar. 2011.

BURGAYA, J. La economia del absurdo. Barcelona: Ediciones Deusto, 2015.

CARCANHOLO, R. Marx, Ricardo e Smith: sobre a teoria do valor trabalho. Vitória (ES): EDUFES, 2012.

CASTELO, R. O novo desenvolvimentismo e a decadência ideológica do pensamento econômico brasileiro. Serviço Social \& Sociedade, São Paulo, n. 112, p. 613-636, out./dez. 2012.

CHESNAIS, F. Mundialização: o capital financeiro no comando. Revista Outubro, São Paulo, n. 5, Instituto de Estudo Socialistas, 2001.

CISLAGHI, J. F. MP 520/2010: Golpe na Saúde Pública e na Democracia. 2011. Disponível em: <http://www.sinmedrj.org.br/2012/clipping/2011/boletim.pdf> DURIGUETTO, M. L. Sociedade civil e democracia: um debate necessário.

Libertas, Juiz de Fora, v.8, n.2, p. 83 - 94, jul-dez / 2008. 
FATORELLI, M. L.; ÁVILA, R. Os números da dívida. Brasília: Auditoria Cidadã da Dívida, 2012.

FATORELLI, M. L.; ÁVILA, R. Os números da dívida. Brasília: Auditoria Cidadã da Dívida, 2014.

GONÇALVES, R. Governo Lula e o nacional desenvolvimentismo às avessas, 2011. Disponível em:

http://www.ie.ufrj.br/oldroot/hpp/intranet/pdfs/texto_nacional_desenvolvimentismo_as_ avessas_14_09_11_pdf.pdf

HARVEY, D. O Novo Imperialismo. São Paulo: Edições Loyola, 2004.

HARVEY, D. O Neoliberalismo: história e implicações. Tradução: Adail Sobral e Maria Stela Gonçalves. São Paulo: Edições Loyola, 2008.

LOPES, M. L. As Medidas Provisórias nº 664 e 665 restringem direitos e confirmam o curso ininterrupto da contrarreforma da previdência social. ADUF Informa, Paraíba, João Pessoa, ed. 114 (edição especial), abril de 2015.

MANDEL, E. Tratado de economia marxista. V. 2. México: Ediciones ERA, 1975.

MANDEL, E. O capitalismo tardio. São Paulo: Nova Cultural, 1982.

MANDEL, E. A Crise do Capital. São Paulo: Unicamp; Ensaio, 1990.

MARX, K.O Capital. Livro 1, vol 1 e 2. Rio de Janeiro, Civilização Brasileira, 1980.

MÉSZÁROS, I. Século XXI - Socialismo ou Barbárie, Boitempo Editorial, São Paulo, 2003, p. 15.

MÉSZÁROS, I. A crise estrutural do capital. Boitempo, São Paulo, 2009.

MOTA, A. E.; AMARAL, A.; PERUZZO, J. O novo desenvolvimentismo e as políticas sociais na América latina, In: MOTA, A. E. (Orgs.) Desenvolvimentismo e Construção de Hegemonia, São Paulo: Cortez 2012.

NETTO, J. P. Crise do Capital e consequências societárias. Serviço Social \& Sociedade. São Paulo, n. 111, jul./set. 2012.

OLIVEIRA, Í. M. de. Cultura política, direitos e política social. In: BOSCHETTI, I. et al. (Orgs.). Política social no capitalismo: tendências contemporâneas. São Paulo: Cortez, 2008.

PAULANI, L. M. Capitalismo financeiro, estado de emergência econômico e hegemonia às avessas no Brasil. In: OLIVEIRA, F.; BRAGA, R.; RIZEK, C. Hegemonia às avessas. São Paulo: Boitempo, 2010.

PEREIRA, P. A. P. Política Social: temas e questões. São Paulo: Cortez, 2011. 
SALVADOR, E. Fundo Público e o financiamento das Políticas Sociais no Brasil. Apresentado no I Simpósio Orçamento Público e Políticas Sociais, no dia 10 de abril de 2012, na Universidade Estadual de Londrina (UEL). Acesso em: < http://www.uel.br/revistas/uel/index.php/ssrevista/article/view/12263 >

SALVADOR, E. Financiamento tributário da política social no pós-real. In: SALVADOR, E. et al. (Org.). Financerização, fundo público e política social. São Paulo: Cortez Editora, 2012, p. 123-152.

SAMPAIO JR., P. de A. Desenvolvimentismo e neodesenvolvimentismo: tragédia e farsa. Serviço Social \& Sociedade, São Paulo, n. 112, p. 672-688, out./dez. 2012. 
Serv. Soc. \& Saúde, Campinas, SP v. 15, n. 1 (21), p. 51-70, jan.jjun. 2016 ISSN 1676-6806 